\title{
System identification modelling based on modification of all terrain vehicle (ATV) using wireless control system
}

\author{
M.S.M. Aras, M.K.M. Zambri, F.A. Azis, M.Z.A. Rashid, M.N. Kamarudin \\ ${ }^{1}$ UTeRG, CERIA, Faculty of Electrical Engineering, Universiti Teknikal Malaysia \\ Melaka (UTeM), Hang Tuah Jaya, 76100 Durian Tunggal, Melaka, Malaysia. \\ *Email: shahrieel@utem.edu.my \\ Phone: +6065552284; Fax: +6065552222
}

\begin{abstract}
This paper describes the modification of all-terrain vehicle (ATV) to semi-autonomous control based on using wireless control system. The semi-autonomous for ATV is based on yaw control. This wireless control system will control the cylinder linear actuator that is added to the ATV. Nowadays, the usage of ATV gives much benefit to their field of work with their design and is dedicated to huge driveability on irregular ground track as well as on paved road. The main problem of the ATV involves the steering control (yaw control), which cannot rotate easily and needs high forces to control the movement of ATV. Yaw movement is very limited when driven manually, since it requires high forces to move the steering. This project begins with a mathematical and empirical modelling to capture the dynamics of a newly modified ATV. In this project, the modelling of ATV by using system identification technique is conducted. The model will then be compared to its derived mathematical model. Then, the design of a wireless control system is required to solve the problem, which results in an easy rotation of $45^{\circ}$ to the left and right with precise, accurate and lightweight yaw movement and verification using MATLAB/Simulink. As a conclusion, the yaw estimation shows that the ATV movement achieved its stability at angle $45^{\circ}$.
\end{abstract}

Keywords: All-Terrain Vehicle; Wireless Control System; yaw control.

\section{INTRODUCTION}

All-terrain vehicle (ATV) is one of the types of vehicle that are much lighter than other four-wheel vehicles, making it popular among expert drivers. This vehicle is also known as a quad bike or four-wheeler or can be defined as a vehicle that travels on low pressure tires [1]. When taking corners, it is more challenging than rugged four-wheel vehicle, thus stabilizing the current ATV is more difficult. As ATV performance is about improving the design and their material equipment, it is better to obtain good performance by getting more knowledge about all the specification information [1]. So, from this knowledge, one method to improve the characteristics of the parameter is by mathematical modelling [1]. Besides the ATV, they may also carry along the farm tool and equipment to move around without any problem. Previous research by [2] that covers the linearity path is used when the farmer needs to do an activity of plant poisoning on their field plant where if the place has many cornering points and uneven ground surface. For the highly linear nature and the large variation in vehicle - terrain interactions, there is limited conventional control technologies in providing satisfactory steering control for off-road vehicles [2]. They can easily use the ATV to carry the tool instead of carrying it himself and moving around. 
Accidents involving ATV total to about 400,000 injuries each year. Of these cases, about 25 percent, or 100,000 people, need medical care. About 800 deaths per year resulted from ATV accidents [3]. A child younger than 16 dies in an ATV accident once every four days $[4,5]$. Agricultural ATV users account for only 20 percent of all riders, but represent 65 percent of occupational ATV-related fatalities, indicating the higher risk associated with agricultural ATV use. Hence, to reduce the numbers of injuries and death from ATV accidents in the future, a wireless remotely controlled ATV needs to be developed. Without riders when controlling the ATV, it is the best way to reduce accidents and damage to the ATV. Prior to this, the ATV has a problem in the steering control, when used in the laboratory, the steering has a problem which is that it cannot move like other vehicles with four wheels.

The problem is that it cannot easily rotate, needs high force to move the steering to complete the movement and also not in accurate position. The movement is very limited when driven manually, since it requires a strong thrust to move the steering. Therefore, the design of wireless control system is required to solve the problem, which is to be able to rotate $45^{\circ}$ to the left and right with precise, accurate position and lightweight steering movement. Hence, in order to improve the performances for both usages of the ATV in the future, the researcher or engineer need data about the current model of ATV and start to accumulate the studies of their behaviour when given the relevant parameters. The high cost of doing this experimental research can also be reduced if the study is done by starting to develop this mathematical modelling [6-13]. If this research is done using some reliable comparing data, it would give much more benefits for future research.

This research aims to model ATV using mathematical modelling and also to design the control system for the ATV as shown in Figure 1 and the specification of ATV is tabulated in Table 1. The modelling of ATV that is going to be used is the single track model or also known as "Bicycle' model. On the other hand, the control system will be designed using wireless control of ATV, which is to achieve better performance in terms of stability and also to reduce workability. Wireless control design for system requires some knowledge about the system. This research attempts to select good transmitter/receiver radio control for an ATV. Today, wireless remote control technology will use facilities like wireless control, automation and telemetry in a variety of industrial applications [14]. On-Off, Up-Down or others can send and receive data using wireless system. The design modelling of ATV involves a mathematical description of the relation among inputs to the process, its state variables, and its output. This description is called the model of the system. The model can be represented as a set of transfer functions for linear time invariant systems or other relationships for non-linear or time variant systems. Mathematical Modelling of complex systems may be a very difficult task [15].

Therefore, the objectives of this research is to model ATV using mathematical modelling and design of wireless control system, which allows the ATV to rotate easily with $45^{\circ}$ to the left and right with precise, accurate and lightweight yaw movement and verification using MATLAB/ Simulink. 


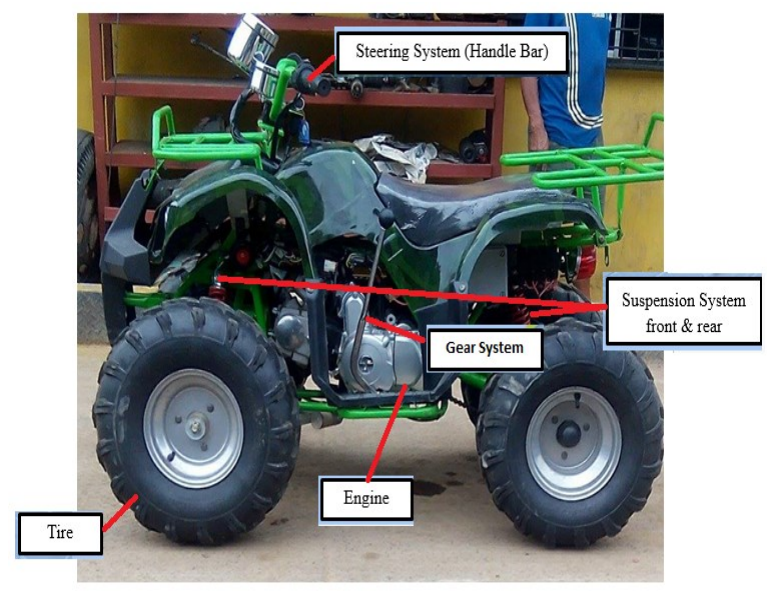

(a)

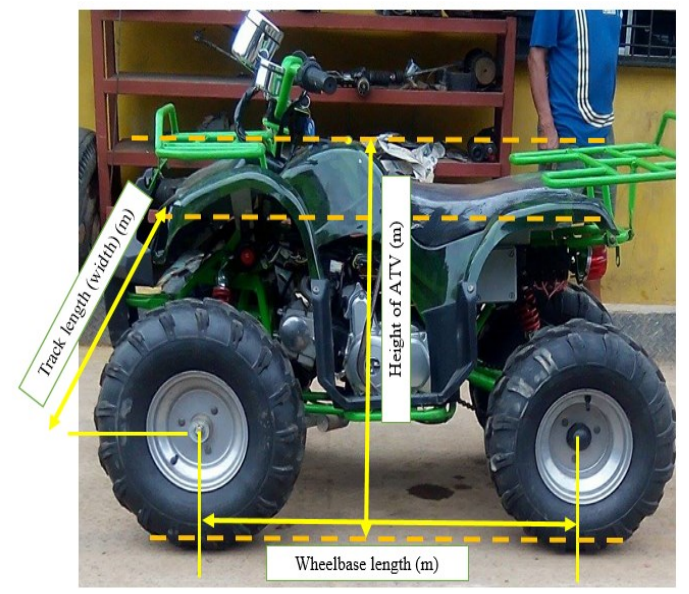

(b)

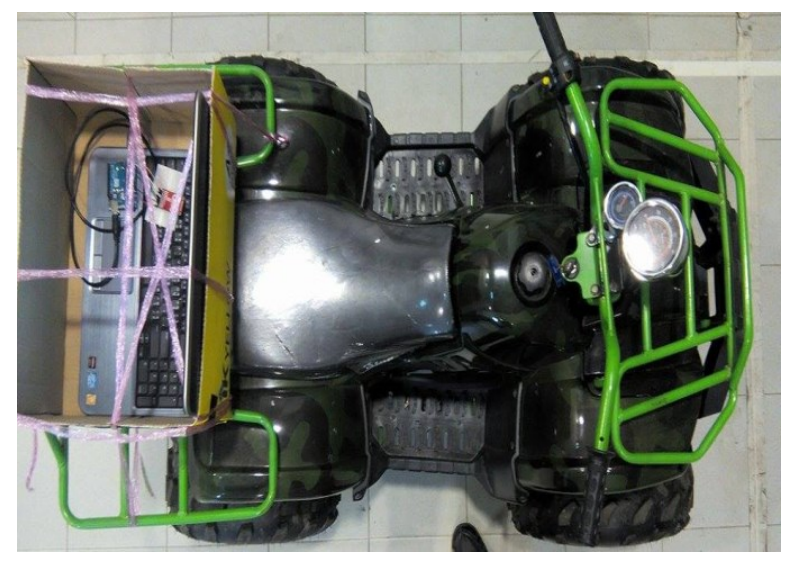

(c)

Figure 1. ATV design specifications.

Table 1. Specifications of ATV.

\begin{tabular}{lc}
\hline \multicolumn{1}{c}{ Specifications of ATV } & Parameters \\
\hline Mass of ATV $(\mathrm{kg})$ & 90.2 \\
Track length $(\mathrm{m})$ & 0.754 \\
Wheelbase length $(\mathrm{m})$ & 0.884 \\
Height of ATV $(\mathrm{m})$ & 0.713 \\
Centre of Gravity & $0.3446 \mathrm{~m}$ from rear wheel \\
Moment of inertia, Ix (kg.m4) & $8.09\left(\mathrm{~kg} \cdot \mathrm{m}^{4}\right)$ \\
Moment of inertia, Iy (kg.m4) & $9.695\left(\mathrm{~kg} \cdot \mathrm{m}^{4}\right)$ \\
Moment of inertia, Iz (kg.m4) & $10.15\left(\mathrm{~kg} \cdot \mathrm{m}^{4}\right)$ \\
Distance COG from the front wheel & $0.5394 \mathrm{~m}$ \\
Distance COG from the rear wheel & $0.3446 \mathrm{~m}$ \\
Cornering stiffness front wheel & $248.07(\mathrm{~N} / \mathrm{rad})$ \\
Cornering stiffness rear wheel & $165.38(\mathrm{~N} / \mathrm{rad})$ \\
\hline
\end{tabular}




\section{MATHEMATICAL MODELING OF ATV}

The single track model is a simple vehicle model which is always used to model fourwheel vehicles as shown in Figure 2 and nomenclatures for single track model as tabulated in Table 2. This modelling shows that the left and right tire characteristics have an equal tire characteristic of a two-wheel in plane vehicle with 2-degrees of freedom (DOF); yaw motion and lateral displacement [16-18]. Below are the assumptions applied on the bicycle model as shown in Figure 3.

1. Heading velocity is constant, $\mathrm{u}(\approx \mathrm{V})$.

2. $\quad$ No slope and body roll.

3. Steering input is constant.

4. Lateral accelerations $\left(4 \mathrm{~m} / \mathrm{s}^{2}\right)$.

5. $\quad$ Sideslip angle $(\beta)$ is assumed small

Table 2. Nomenclatures for single track model.

\begin{tabular}{|c|c|}
\hline Symbol & Descriptions \\
\hline$K_{\text {steer }}$ & $\begin{array}{l}\text { Steering ratio; ratio between the turn of the steering wheel and the angular } \\
\text { displacement of the wheel. }\end{array}$ \\
\hline $\mathrm{C} 1$ or $C_{f}$ & Cornering stiffness front \\
\hline $\mathrm{C} 2$ or $C_{r}$ & Cornering stiffness rear \\
\hline I & Moment of inertia about vertical axis \\
\hline$\beta$ & Sideslip angle \\
\hline$a_{y}$ & Lateral acceleration \\
\hline$\delta$ & Angle steering \\
\hline $\mathrm{a}$ & Distance of front axle to Centre gravity \\
\hline $\mathrm{b}$ & Distance of rear axle to Centre gravity \\
\hline $\mathrm{I}_{\mathrm{z}}$ & Yaw of inertia \\
\hline$l_{\mathrm{f}}=l_{r}$ & Distances from the centre of gravity to the front and rear axles respectively. \\
\hline $\mathrm{F}_{\mathrm{F}}$ & Lateral tire force front \\
\hline $\mathrm{F}_{\mathrm{R}}$ & Lateral tire force rear \\
\hline $\mathrm{U}$ or $\mathrm{u}$ & Velocity forward \\
\hline $\mathrm{r}$ & Yaw of velocity \\
\hline $\mathrm{M}$ or $\mathrm{m}$ & Mass \\
\hline $\mathrm{N}$ & Rotational Speed \\
\hline
\end{tabular}

So, the equation of motion of the bicycle model is derived as in Eq. (1).

Reference from $\mathrm{Y}$-axis

$$
\begin{aligned}
& m(\dot{v}+u r)=F_{F_{y}}+F_{R_{y}} \\
& I \dot{r}=a F_{F_{y}}-b F_{R_{y}}
\end{aligned}
$$

The force acting on tire:

$$
\begin{aligned}
& F_{F_{y}}=C_{f} \alpha_{1} \\
& F_{R_{y}}=C_{r} \alpha_{2}
\end{aligned}
$$

where, 


$$
\alpha_{1}=+\delta-\frac{1}{u}(v+a r), \alpha_{2}=-\frac{1}{u}(v+b r), C_{f}=\frac{a}{l}, C_{r}=\frac{b}{l}
$$

To derived the steering angle, $\delta$ :

Substitute of $F_{F_{y}}$ and $F_{R_{y}}$ in Eq. (1) and (2)

$$
\begin{aligned}
& m(\dot{v}+u r)=-\frac{v}{u}\left(C_{f}+C_{r}\right)+\frac{r}{u}\left(b C_{r}-a C_{f}\right)+\delta C_{f} \\
& I \dot{r}=-\frac{r}{u}\left(a^{2} C_{f}+b^{2} C_{r}\right)-\frac{v}{u}\left(a C_{f}-b C_{r}\right)+a \delta C_{f}
\end{aligned}
$$

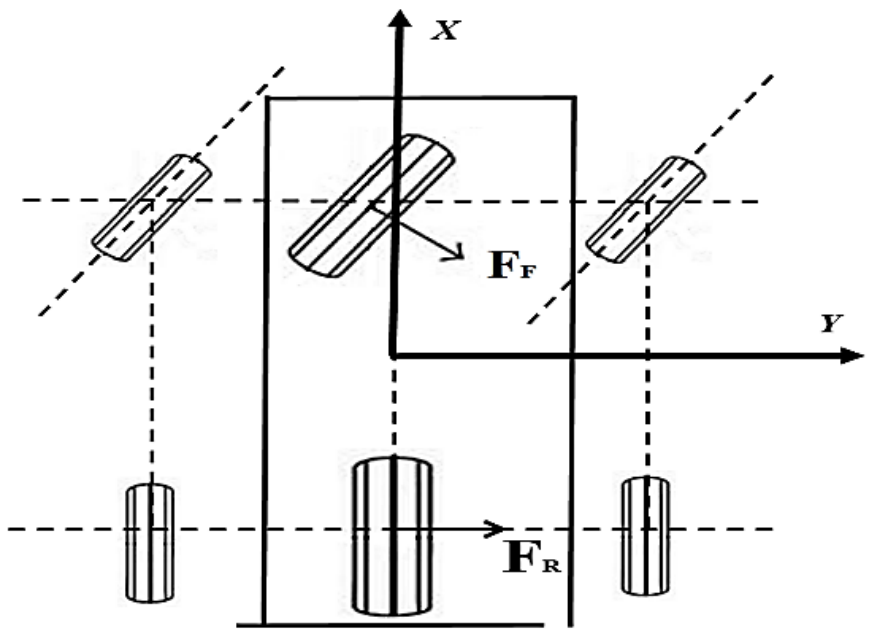

Figure 2. From Top view: Single track part will be taken at middle vertical X-axis as reference modelling.

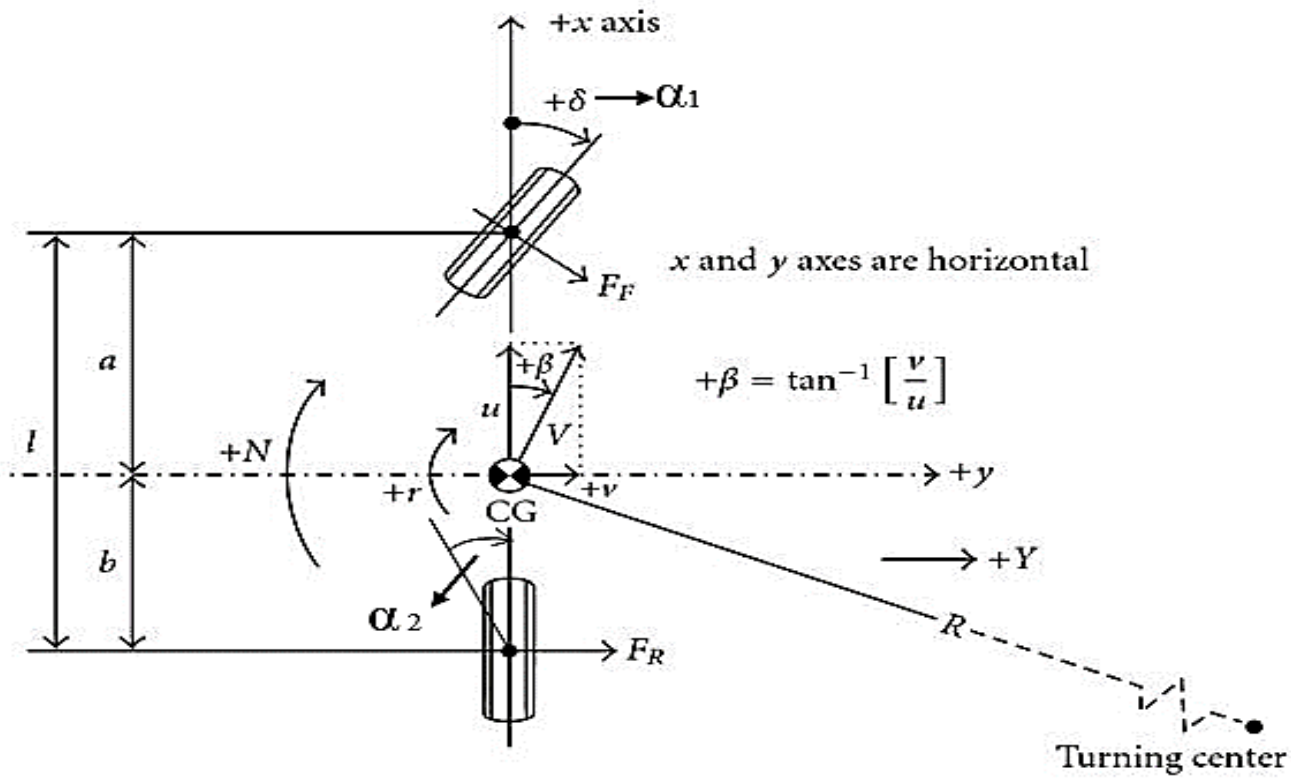

Figure 3. The reference modelling is analyse by add some parameter and is known as "Bicycle Model".

Combine Eq. (6) and Eq. (7) to eliminate $v$ : 
$m u I \ddot{r}+\left[I\left(C_{f}+C_{r}\right)+m\left(a^{2} C_{f}+b^{2} C_{r}\right)\right] \dot{r}+\frac{1}{u}\left[C_{f} C_{r} l^{2}-m u^{2}\left(a C_{f}-b C_{r}\right)\right] r=$ $\operatorname{muaC}_{f} \dot{\delta}+C_{f} C_{r} l \delta$

The circle test conditions:

$$
\ddot{r}=0 \quad \dot{r}=0 \quad \dot{\delta}=0
$$

Then,

$\frac{r}{u}\left[C_{f} C_{r} l^{2}-m u^{2}\left(a C_{f}-b C_{r}\right)\right]=C_{f} C_{r} l \delta$

And from Eq. (10), the $\delta$ is derived:

$+\delta=\frac{L}{R}-\frac{m v^{2}}{R l}\left(\frac{a}{C_{r}}-\frac{b}{C_{f}}\right)$

$a_{y}=\frac{v^{2}}{R}$

By replacing $a_{y}$ in Eq. (12),

$\delta=\frac{L}{R}-\frac{m a_{y}}{l}\left(\frac{a}{C_{r}}-\frac{b}{C_{f}}\right)$

The equation of $\beta$ is derived from the front slip angle:

$$
\begin{aligned}
& +\beta=-\frac{v}{u} \\
& \alpha_{2}=-\frac{1}{u}(v-b r)=+\beta+\frac{b r}{u} \\
& +\beta=-\frac{b}{r}+\alpha^{2}
\end{aligned}
$$

And from the Eq. (3)

$\beta=-\frac{b}{r}+\frac{\alpha m a_{y}}{C_{r} L}$

Eq. (13) and Eq. (17) show that $+\beta$ and $+\delta$ are linearly dependent on lateral acceleration $\mathrm{a}_{\mathrm{y}}$. To describe the dynamic behaviour of the ATV model, a state space model is used. The state space model can be written as:

$\dot{x}=A x+B u$

$y=C x+D u$

Where:

$$
x=\left|\begin{array}{l}
v \\
r
\end{array}\right|, \quad y=\left|\begin{array}{c}
a_{y} \\
r
\end{array}\right|, \quad u=\delta
$$

And, 
$A=-\left|\begin{array}{cc}\frac{C_{f}+C_{r}}{m u} & u+\frac{a C_{f}-b C_{r}}{m u} \\ \frac{a C_{f}-b C_{r}}{I_{z} u} & \frac{a^{2} C_{f}+b^{2} C_{r}}{u I_{z}}\end{array}\right| B=\left|\begin{array}{c}\frac{C_{f}}{m} \\ \frac{a C_{f}}{I_{z}}\end{array}\right| C=-\left|\begin{array}{cc}\frac{C_{f}+C_{r}}{m u} & \frac{a C_{f}-b C_{r}}{m u} \\ 0 & -1\end{array}\right| D=\left|\begin{array}{c}\frac{C_{f}}{m} \\ 0\end{array}\right|$

\section{MODIFICATION OF THE ATV}

\section{ATV configurations}

To design a wireless control system, there are actually three different parts with different functions and they contribute to the control differently. The wireless control systems covered for steering system (handle bar), switching system and brake system are shown in Figure 4.

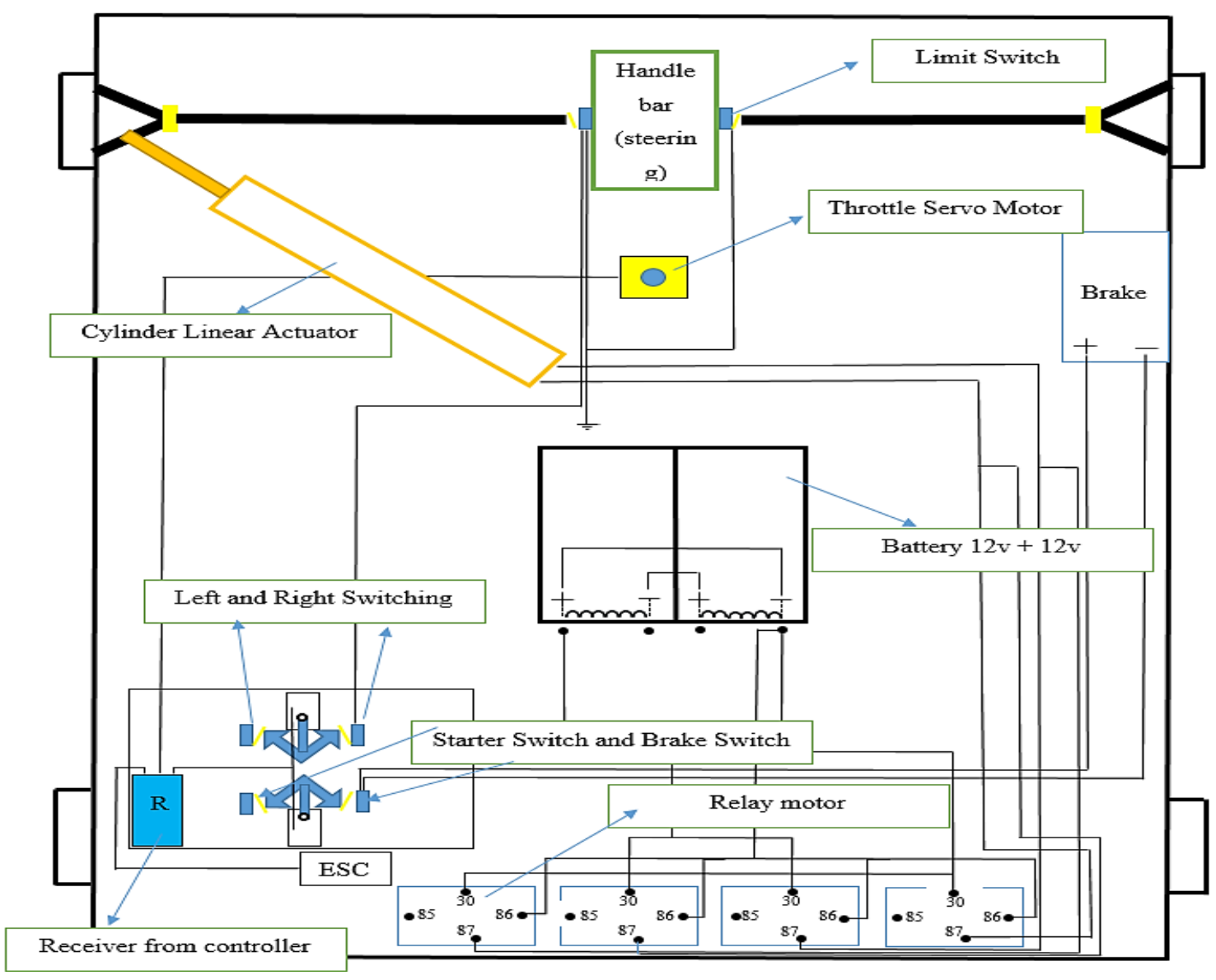

Figure 4. Modification of ATV configurations.

\section{Cylinder Linear Actuator}

Basic linear cylinders are used to provide straight-line, in/out linear movement for a variety of applications as shown in Figure 5. They are available as single acting (spring extend or spring return) and double acting styles with single rod or double rod configurations, non-rotating, and precision non-rotating models. Body styles include crimped, round, or tie rod. Single acting cylinders develop thrust in one direction and have lower air consumption compared to the equivalent size of double acting cylinders. With a double acting air cylinder, air pressure may be alternately applied to provide force in both directions. The specifications of cylinder linear actuator are tabulated in Table 3. 


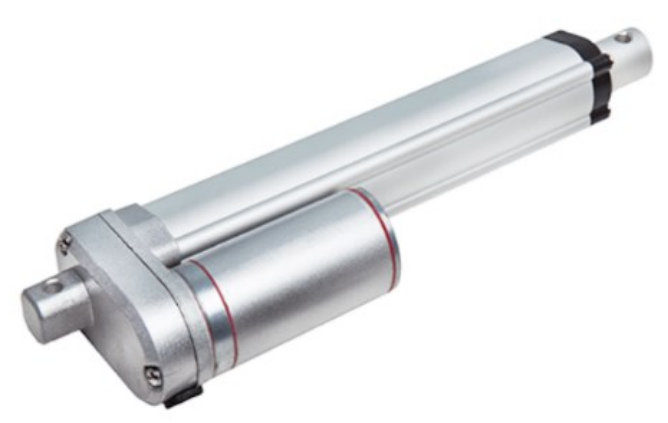

Figure 5. Cylinder linear actuator.

Table 3. Specifications of cylinder linear actuator.

\begin{tabular}{ll}
\hline Items & Specifications \\
\hline Series & LT \\
Capacity & 27 to $225 \mathrm{lbs}(120$ to $1000 \mathrm{~N})$ \\
Voltages & $12 \mathrm{Vdc}$ or $24 \mathrm{Vdc}$ \\
Std. Stroke & 1 to 11.8 in \\
Lengths (inch) & $(25 \mathrm{~mm}$ to $300 \mathrm{~mm})$ \\
Max Speed at Rated Load & Up to $1.3 \mathrm{in} / \mathrm{s}(33 \mathrm{~mm} / \mathrm{s})$ \\
Limit Switches & Fixed \\
Feedback & Hall effect sensor or potentiometer optional \\
Current Draw at Rated Load & $3.5 \mathrm{~A}(12 \mathrm{Vdc})$ \\
& $2.0 \mathrm{~A}(24 \mathrm{Vdc})$ \\
Translating Tube Material & Polished Aluminium \\
Temperature Range & $-13^{\circ} \mathrm{F}$ to $150^{\circ} \mathrm{F}$ \\
& $\left(-25^{\circ} \mathrm{C}\right.$ to $\left.65^{\circ} \mathrm{C}\right)$ \\
\hline
\end{tabular}

\section{System Integration with Sensor}

The measured data for every test is based on the suitable selection of the sensor. The system integration of ATV with the sensor will be carried out by some experiments. However, the proposed for selection of sensor that is going to be used is accelerometer and gyro sensor. Thus, in order to integrate the sensor at the same time while conducting the experiment, the 3-DOF of inertial measurement unit (IMU) is selected as shown in Figure 6. The function of IMU is to detect the rate of acceleration, as well as the changes on rotational attributes such as pitch, roll and yaw. Then, the data are fed into a computer to calculate the current speed and position given a known initial speed and position. For the 3- DOF IMU, the sensors configurations are one gyroscope that measures yaw with two accelerometers. Since, the project is focused on a linear single track model, the pitch and roll of the vehicle is ignored. 


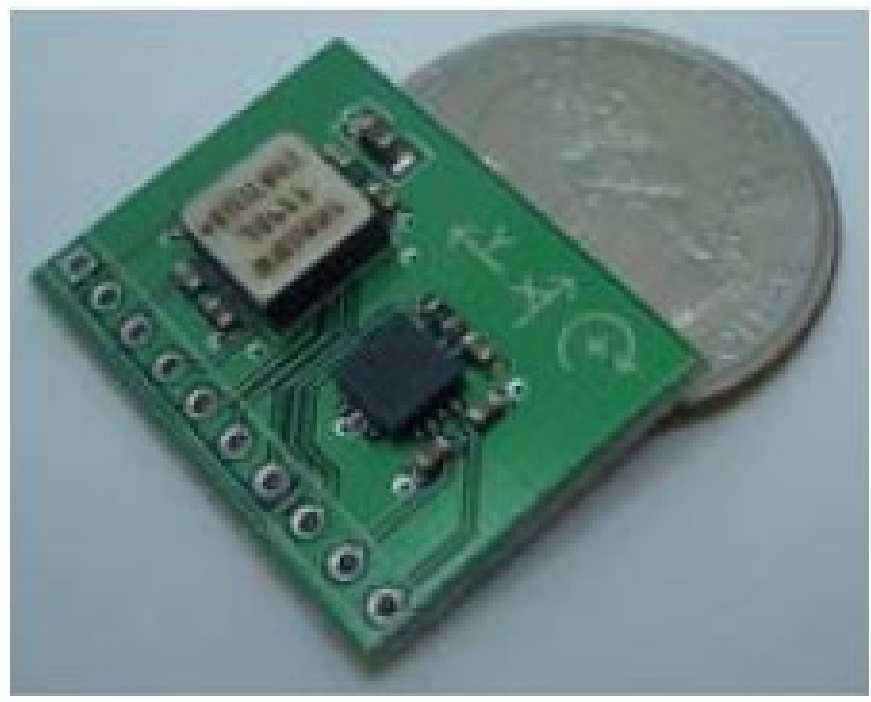

Figure 6. 3-DOF IMU sensors.

\section{Controller Design- Multi-channel wireless radio control}

There are two types of radio controller known as single channel and multi-channel. Multichannel wireless radio control selected to be used in this project is shown in Figure 7. This type is used to transmit in more complicated tasks and useful signals to a piece of remote equipment - for example, to make a radio-controlled car speed up, slow down, or steer from side to side. Instead of just sending a basic on/off signal, it transmits a series of coded analogue or digital pulses that are decoded by the receiver and used to produce specific actions. For example, turning a steering wheel on a radio-control transmitter sends a series of pulses that make an electric motor rotate by a corresponding amount to steer a radio-controlled car one way or the other. Motors that work this way are known as servo motors.
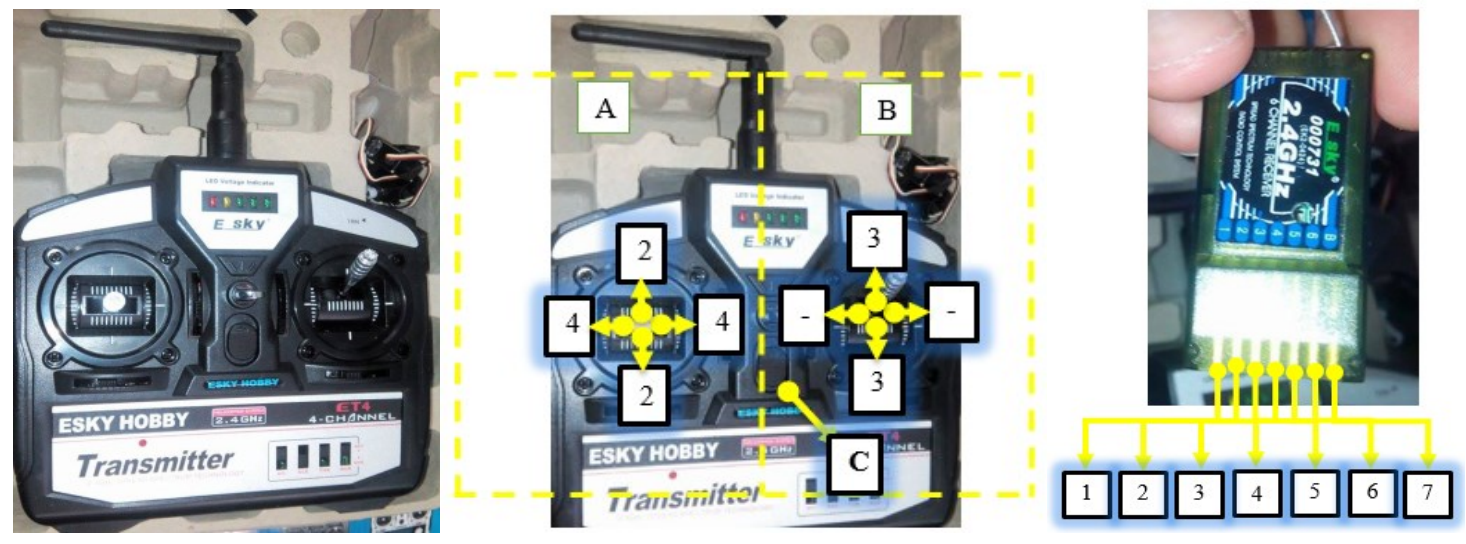

Figure 7. Multi-channel wireless radio control.

In this project, radio wireless control system will be used to have the process of transmitting information from one location to another location without using any wire or cable connection. It is also known as wireless communication systems. Radio control systems are very important in the field of manufacturing, which can reduce the number of employees to perform certain tasks. This transmitter and receiver are used as the 
controller part, which is controlled by wireless communication. The distance and frequency to control between the ATV is around of $1 \mathrm{~km}$ and $2.4 \mathrm{GHz}$ for wave of frequency. This transmitter and receiver have their own connection. The connection is known as channel. This system will be using six channels to control the ATV as shown in Figure 7. The transmitter and receiver have their own connection, the transmitter will send the signal by the frequency within range of $2.4 \mathrm{GHz}$ to the receiver through the channel that is defined by ourselves.

\section{RESULTS AND DISCUSSION}

The experiments of yaw stability are shown in Figure 8. The ATV climbs the slope up and down. The total distance for yaw stability is about $2 \mathrm{~m}$. The height for track testing is $0.4 \mathrm{~m}$. After that, using a measuring tape, the track is set up. Then, using masking tape, the three cupboards are affixed together. Next, in order to vary the height of platform for the angle of slopes, a group of stacking object put under the platform until reaching the desired height. The height of the platform is taken and tabulated in a table of data and is indicated in the graph as shown in Figure 9. The SD card module and IMU sensor are connected with ARDUINO UNO and breadboard. Then, the coding of combination of SD card module, IMU sensor will upload and connect with the computer and will be mounted onto the ATV. The data collected are stored in the SD card module. Then, the data collected are used in system identification toolbox to infer an ATV model as shown in Figure 10. The best fit for system identification is approximately $70 \%$. Then, this data are selected to infer a model of ATV. As to calculate the forward velocity of the ATV, the timer will be set and the time taken for the ATV travelled along the track will be taken before and after the experiment as shown in Figures $11-13$. Figure 11 shows the ATV tested for turning left and right and adjusted throttle. Figure 12 shows the real time experiment of ATV climbing the slope while Figure 13 shows the outdoor testing for ATV.

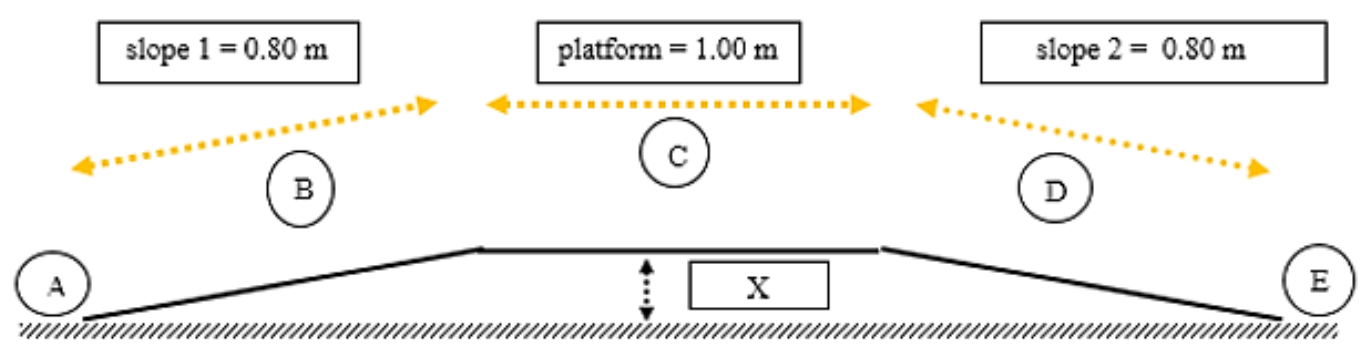

Figure 8. Track testing for ATV.

Based on [19], the model of ATV is obtained using the system identification technique. The experiments were done based on open loop system and implemented in system identification MATLAB toolbox for the mathematical modelling of the ATV based on the single track model. By using Eq. (20) and the model state-space for the yawing are:

$A=-\left[\begin{array}{cc}8.99 & 1.246 \\ 50.97 & 16.96\end{array}\right] \quad B=\left|\begin{array}{l}3.32 \\ 44.5\end{array}\right| C=-\left[\begin{array}{cc}8.99 & 0.6676 \\ 0 & -1\end{array}\right] \quad D=\left|\begin{array}{c}3.316 \\ 0\end{array}\right|$ 


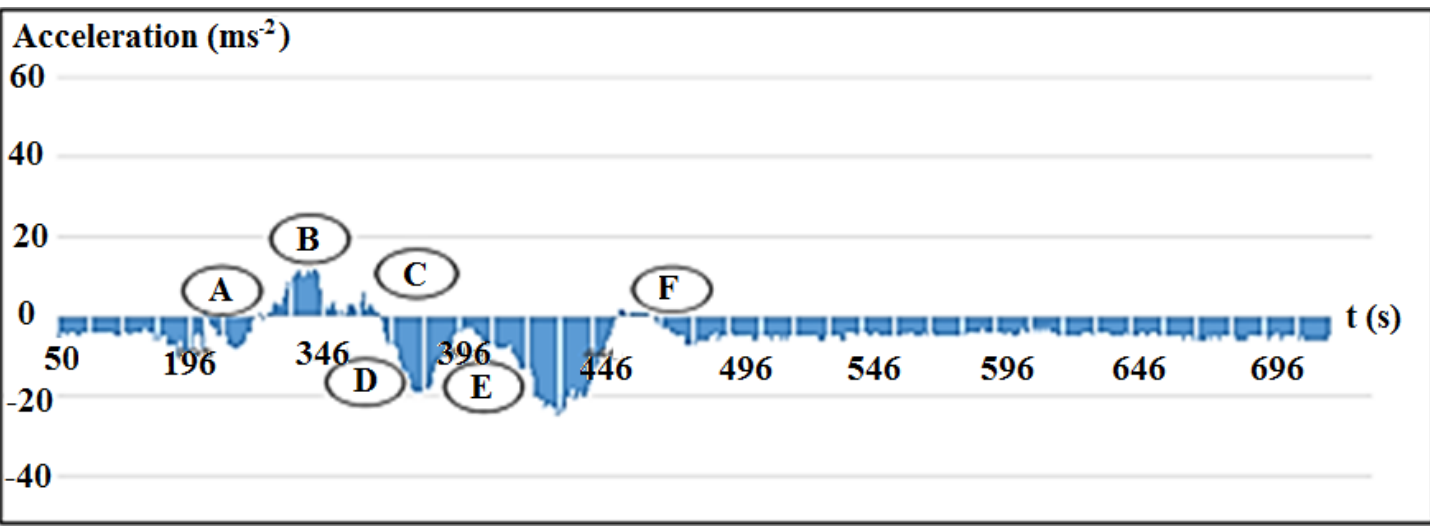

Figure 9. Data collected using IMU sensor.
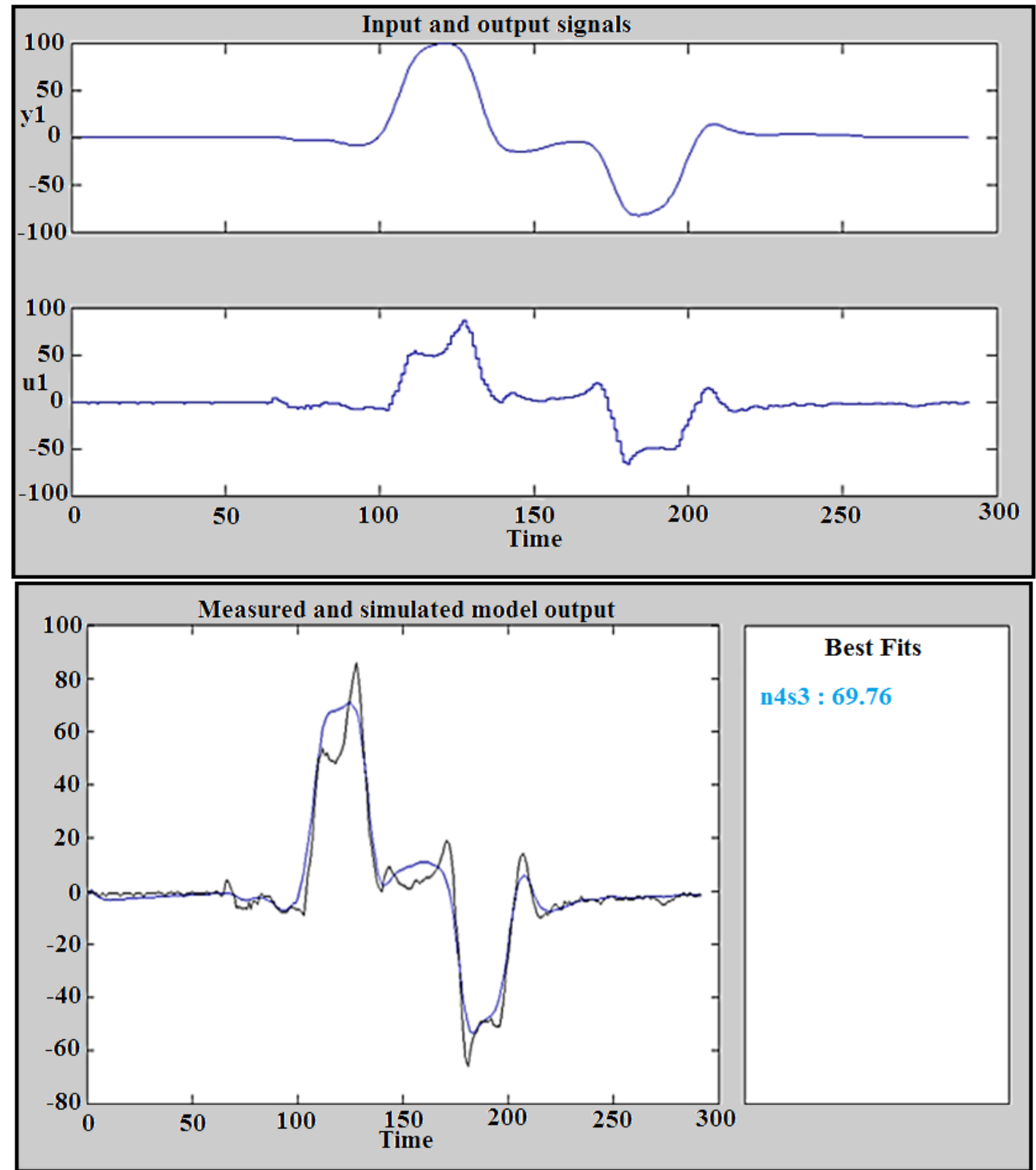

Figure 10. MATLAB System identification toolbox. 

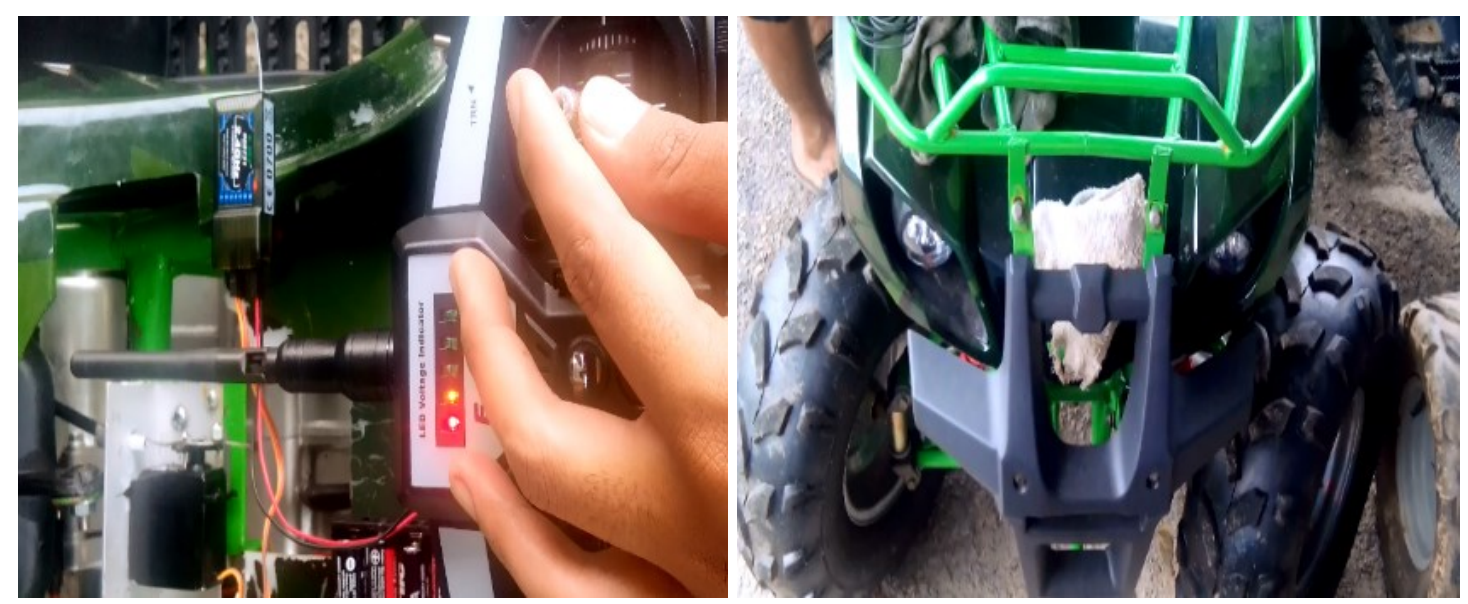

Figure 11. Testing transmitter for throttle control for ATV.
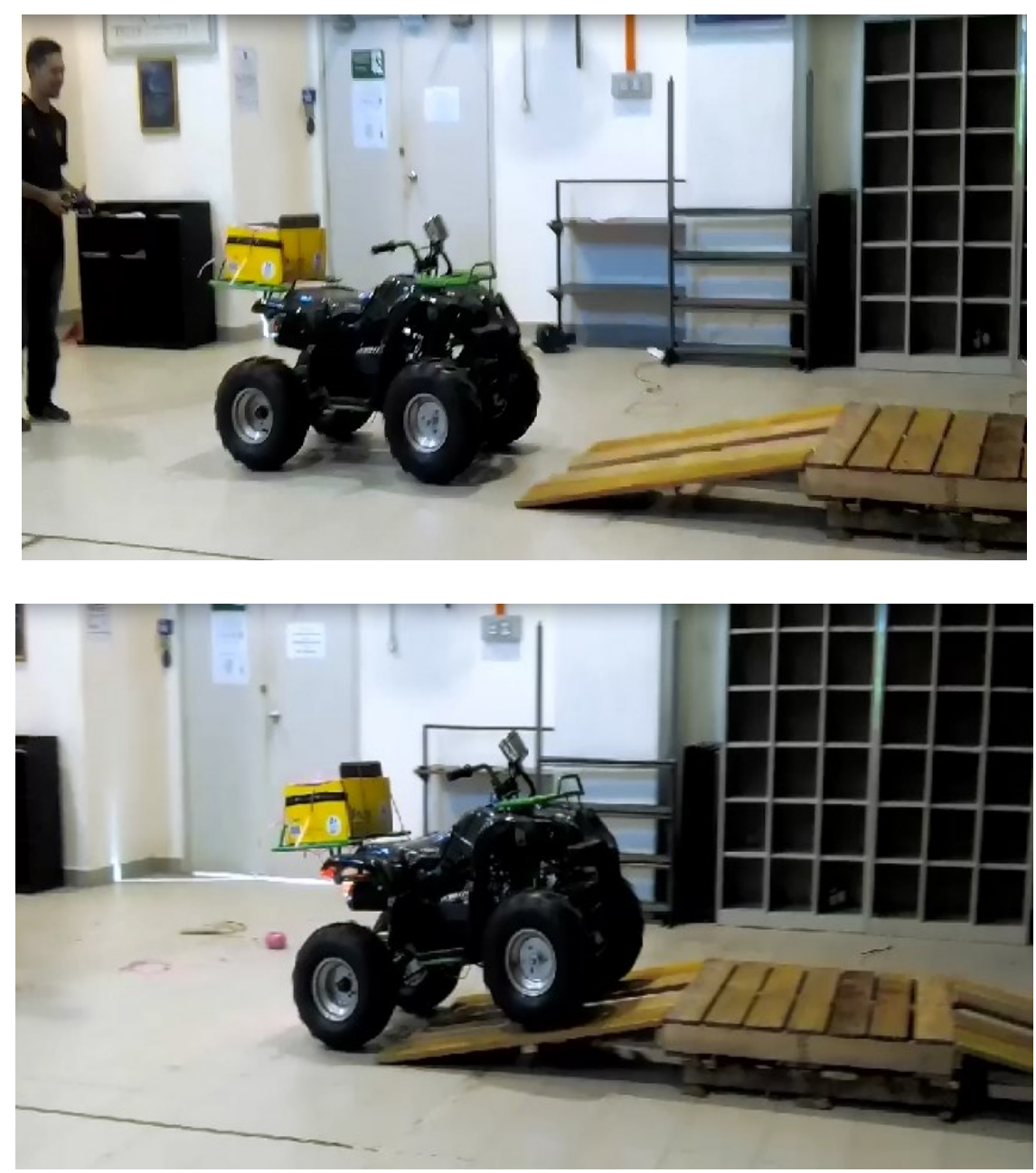

Figure 12. ATV testing for yaw stability.

The model in Eq. (21) obtained from system identification technique will be analysed in terms of controllability and observability and also asymptotical stability. Based on state space matrices in Eq. (21), the system is both controllable and observable because the system has a rank of 2 . This system is asymptotically stable when all 
eigenvalues of $A$ have negative real parts. Also, Eq. 21 can be written as transfer function as shown in Eq. (22).

$$
T_{f}=\frac{3.316 S^{2}+26.495 s+133.159}{s^{2}+25.95 s+88.962}
$$
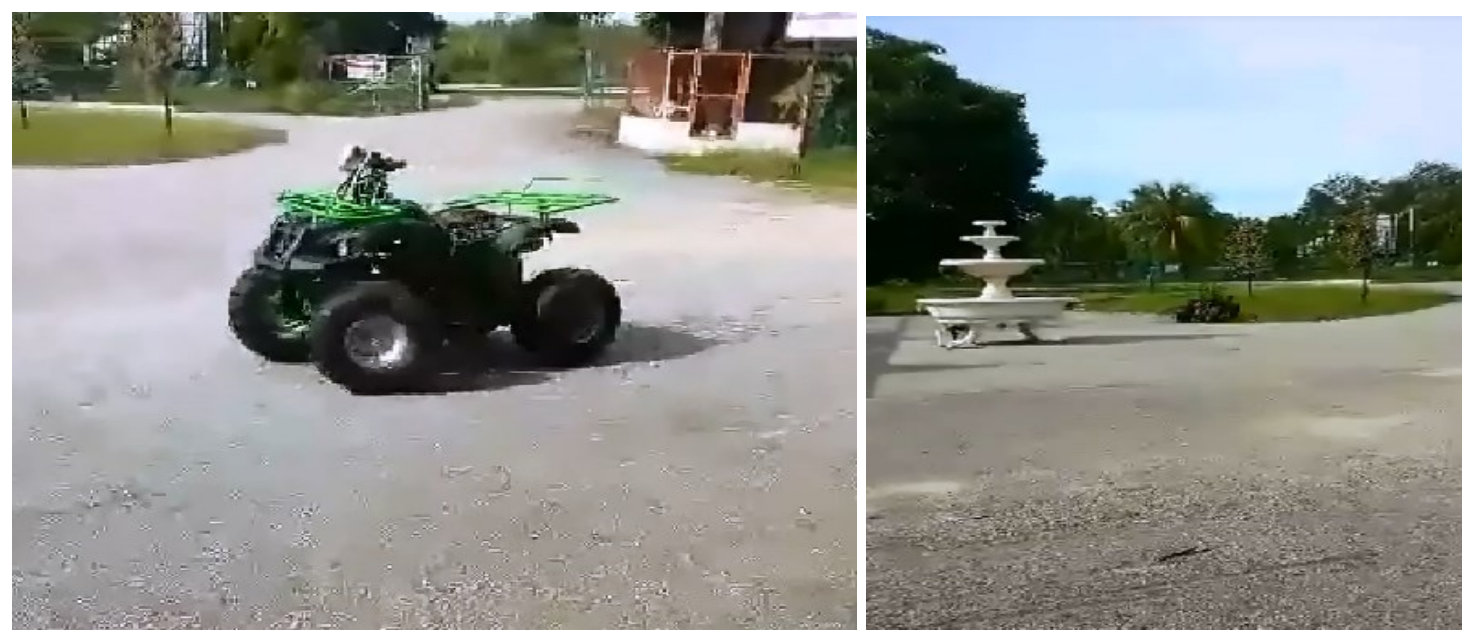

Figure 13. Outdoor testing.

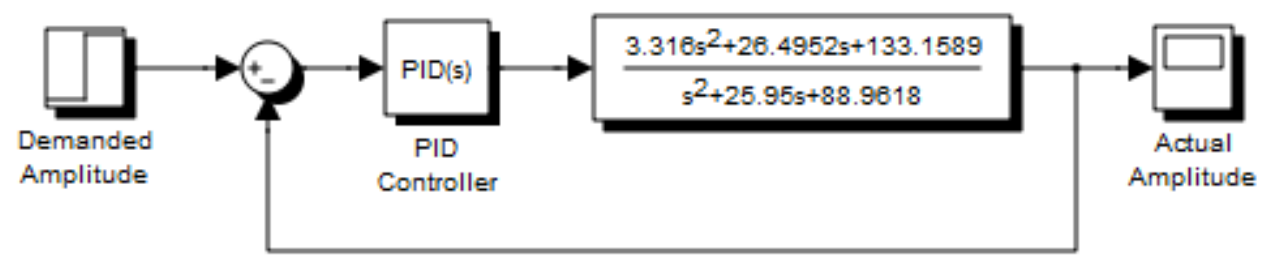

Figure 14. Block diagram for simulation of ATV model using MATLAB/Simulink.

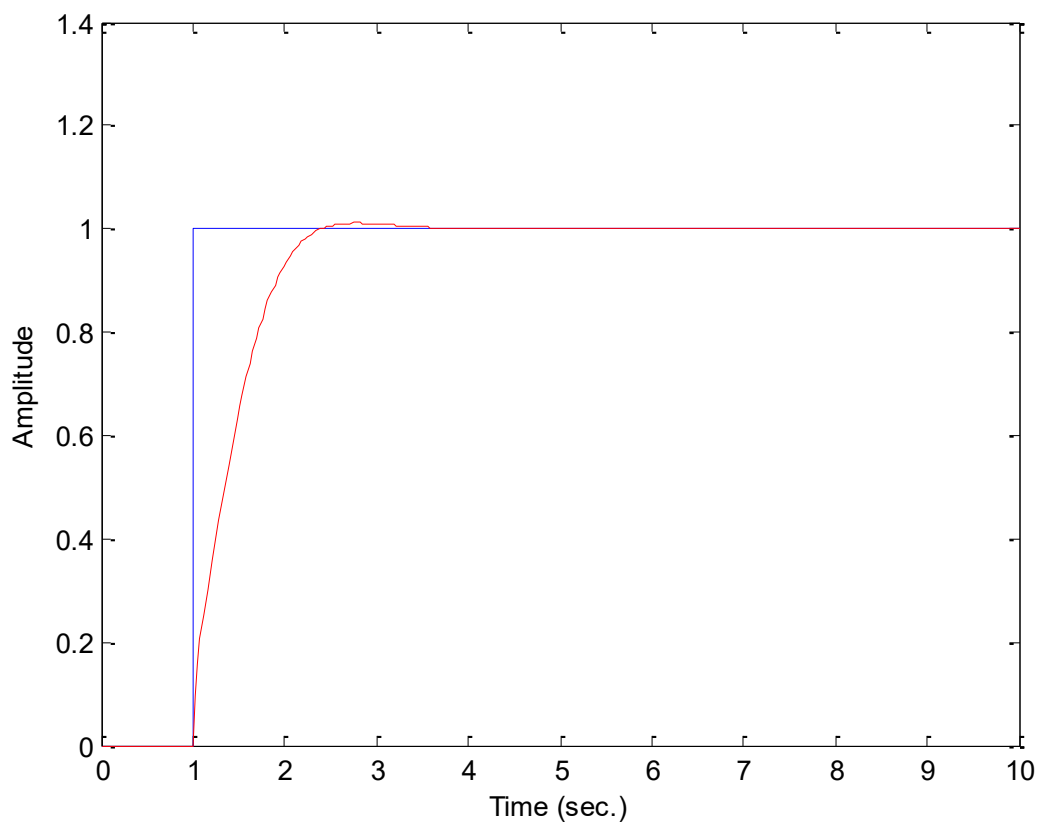

Figure 15. System response of ATV model based on sytem identification technique. 
Figure 14 shows the block diagram for simulation of ATV model using MATLAB/ Simulink. This ATV model is based on Eq. 22. Figure 15 shows the system response of the ATV model based on system identification technique where the conventional PID controller is used. The parameter of PID controller is tuned manually to 0.1 for proportional gain, 3 for integral gain and 0.1 for derivative gain. Small overshoot in the system response is less than $5 \%$ and this controller is acceptable to use.

\section{CONCLUSIONS}

This project begins with a mathematical and empirical modelling to capture the dynamics of a newly modification ATV. The stability of the ATV is analysed based on the yaw motion. The data based on the experiment for yaw motion, used to infer an ATV model using MATLAB system identification toolbox and useful to design the controller for ATV. The modification of all-terrain vehicle (ATV) to semi-autonomous control based on using wireless control system is successful designed. Therefore, the design of wireless control system can rotate easily with $45^{\circ}$ to the left and right with precise, accurate and lightweight yaw movement. The yaw estimation shows that the ATV movement achieved its stability at angle $45^{\circ}$.

\section{ACKNOWLEDGEMENT}

The authors would like to be obliged to Universiti Teknikal Malaysia Melaka (UTeM) especially for Underwater Technology Research Group (UTeRG), Centre of Research and Innovation Management (CRIM) for providing laboratory facilities and financial assistance under project no. PJP/2013/FKE (14A)/S01200.

\section{REFERENCES}

[1] Commission UCPS. Standards for all terrain vehicles and ban of three-wheeled all terrain vehicles; Notice of Proposed Rulemaking. Federal Register. 2006;71:45904-62.

[2] Forouhar F. All-terrain vehicles frequency domain response analysis and rider behavior. Proceedings of the IEEE International Conference on Control Applications. 1997. p. 183-8.

[3] Cooper C. ATC90 History. Archived from the original on. 2006;16.

[4] Control CfD, Prevention. All-terrain vehicle fatalities--West Virginia, 1999-2006. MMWR: Morbidity and Mortality Weekly Report. 2008;57:312-5.

[5] Ganos D, Crady S, Poortenga S, Hoffman G, Mann R. Trauma associated with three-and four-wheeled all-terrain vehicles: is the four-wheeler an unrecognized health hazard? The American Surgeon. 1988;54:429-33.

[6] Mohd T, Hassan M, Aziz W. Mathematical modeling and simulation of an electric vehicle. Journal of Mechanical Engineering and Sciences. 2015;8:1312-21.

[7] Ali FA, Aras M, Shahrieel M, Ab Azis F, Sulaima MF, Jaafar I. Design and development of auto depth control of remotely operated vehicle using thrusters system. Journal of Mechanical Engineering and Sciences. 2014:1141-9.

[8] Rahmat MS, Ahmad F, Mat Yamin AK, Aparow VR, Tamaldin N. Modeling and torque tracking control of permanent magnet synchronous motor (PMSM) for hybrid electric vehicle. International Journal of Automotive and Mechanical Engineering. 2013;7:955-67. 
[9] Nagarkar MP, Vikhe GJ, Borole KR, Nandedkar VM. Active control of quarter car suspension system using linear quadratic regulator. International Journal of Automotive and Mechanical Engineering. 2011;3:364-72.

[10] Bakhtiari-Nejad F, Nazemizadeh M, Arjmand H. Tracking control of an underactuated gantry crane using an optimal feedback controller. International Journal of Automotive and Mechanical Engineering. 2013;7:830-9.

[11] Abdullah MA, Zainordin AZ, Hudha K. Performance evaluation of shaft speed control using a magnetorheological brake. International Journal of Automotive and Mechanical Engineering. 2015;11:2654-63.

[12] Mohd Amin A-T, Mohamed Haris S, Mohd Nopiah Z. Stability of a switched linear system. Journal of Mechanical Engineering and Sciences. 2012;3:320-30.

[13] Ariff MHM, Zamzuri H, Nordin MAM, Yahya WJ, Mazlan SA, Rahman MAA. Optimal control strategy for low speed and high speed four-wheel-active steering vehicle. Journal of Mechanical Engineering and Sciences. 2015;8:1516-28.

[14] Andrew-Munot M, Ibrahim R. Remanufacturing process and its challenges. Journal of Mechanical Engineering and Sciences. 2013;4:488-95.

[15] Sailan K, Kuhnert KD, Karelia H. Modeling, design and implement of steering fuzzy PID control system for DORIS robot. International Journal of Computer and Communication Engineering. 2014;3:57.

[16] Bistrov V. Performance analysis of alignment process of MEMS IMU. International Journal of Navigation and Observation. 2012;2012.

[17] Geng Y, Martins R, Sousa J. Accuracy analysis of DVL/IMU/magnetometer integrated navigation system using different IMUs in AUV. 8th IEEE International Conference on Control and Automation. 2010. p. 516-21.

[18] Dhuri C, Masur A, Warang A, sudhir A. Selection, Modification and Analysis of Steering Mechanism for an All - Terrain Vehicle. International Journal on Theoretical and Applied Research in Mechanical Engineering 2013;2:69-73.

[19] Azis F, Aras M, Rashid M, Khamis KS, Ghani O, Othman MN. Modelling and Analysis of All Terrain Vehicle (ATV) Using System Identification for Yaw Stability. Applied Mechanics and Materials2015. p. 221-6. 